Delft University of Technology

\title{
General Considerations for the Execution of Load Tests
}

Lantsoght, Eva; Schmidt, J.W.

\section{Publication date \\ 2019}

Document Version

Accepted author manuscript

Published in

Load Testing of Bridges

\section{Citation (APA)}

Lantsoght, E., \& Schmidt, J. W. (2019). General Considerations for the Execution of Load Tests. In E. Lantsoght (Ed.), Load Testing of Bridges: Current Practice and Diagnostic Load Testing (Vol. 12). CRC Press / Balkema.

\section{Important note}

To cite this publication, please use the final published version (if applicable).

Please check the document version above.

\section{Copyright}

Other than for strictly personal use, it is not permitted to download, forward or distribute the text or part of it, without the consent of the author(s) and/or copyright holder(s), unless the work is under an open content license such as Creative Commons.

\section{Takedown policy}

Please contact us and provide details if you believe this document breaches copyrights.

We will remove access to the work immediately and investigate your claim. 


\title{
Chapter 6. General considerations for the execution of load tests
}

\author{
E.O.L. Lantsoght
}

Politécnico, Universidad San Francisco de Quito, Quito, Ecuador \& Concrete Structures, Delft University of Technology, Delft, the Netherlands

Jacob Wittrup Schmidt

Danish Technical University, Kongens Lyngby, Denmark

ABSTRACT: This chapter discusses the aspects related to the execution of load tests, regardless the chosen type of load test. The main elements required for the execution of the load test are the equipment for applying the load and the equipment for measuring and displaying (if required) the structural responses. This chapter reviews the commonly used equipment for applying the loading, and discusses all aspects related to the measurements. The next topic is the practical aspects related to the execution. This topic deals with communication on site during the load test, and important safety aspects during a load test.

\section{INTRODUCTION}

This chapter introduces the general aspects that all load tests have in common for their execution. Particularities for diagnostic load testing are discussed in Part III and for proof load testing in Part IV. The determination of the target load during the test is different for diagnostic and proof load testing, and is discussed in the relevant chapters. This chapter will in particular discuss possible methods for applying the load and the equipment necessary for the presented methods. Depending on the magnitude of the target load and bridge geometry, some load applications will be more suitable than others. It is therefore the aim of this chapter to qualitatively describe which load methods are more suitable for larger load magnitudes.

A second section in this chapter contains the general considerations related to the measurement equipment. The development of the sensor plan is closely related to the goals of the load test, and will be different for diagnostic load testing and proof load testing. Therefore, a special focus is on a discussion of the general requirements that the equipment (sensors and data acquisition and visualization equipment) should fulfil for use in a load test.

A final section of this chapter deals with the practical aspects related to the execution of a load test. During the load test, the communication between all parties involved and present in 
the field is important. The safety during the execution of the load test should also be considered at all times. The safety of the traveling public and the parties involved with the execution of the load test is discussed. The structural safety needs to be monitored during the load test, and the attention that needs to be paid to the structural responses during a load test depends on the magnitude of the load (and as such, on the type of load test). For diagnostic load testing, a verification of the linearity of the responses and comparison to the analytically predicted responses may be sufficient, whereas for proof load testing the structural safety requires checking the stop criteria. These aspects are discussed further in Part III for diagnostic load tests and in Part IV for proof load tests.

It is good practice to keep the general considerations for the execution of load tests in mind during the preparation stage of the load test. As such, the testing engineers can prepare a planning for the execution to ensure a smooth process in the field.

\section{LOADING EQUIPMENT}

Depending on the goals of the load test, several options are available to apply the load. For static load tests, dead loads, loading vehicles, and a system with hydraulic jacks can be used. For dynamic load tests, vehicles, a group of pedestrians (for pedestrian bridges), or an external source of excitation can be used. The elements important for the preparation are discussed in Chapter 5 .

Dead loads are only suitable for static load tests. However, dead loads are not commonly used for bridge load testing, as applying these loads is time-consuming, and arching can occur in the loads which makes the loading of the bridge ineffective. Additionally, the loading method is difficult to control if deformations rapidly increase during testing and could lead to collapse. Consequently, high magnitudes of dead loads do not have an inherent safety against collapse. For proof load testing, the use of a system with hydraulic jacks is to be preferred as high staticand cyclic loads can be applied in a controlled manner. Hydraulic jacks can however be combined with dead loading in a desirable way when high magnitude loading is applied as shown in Chapter 5. Dead load, using distributed loading for static load tests, is typically used for proof load testing of buildings, for load testing of the sidewalks of bridges, and for load testing of pedestrian bridges.

Load testing of bridges is mostly done by utilizing loading vehicles. Loading vehicles can be used for diagnostic and proof load testing. The advantage of using loading vehicles is that they can easily be placed at different positions and in different configurations, and that the test can 
easily be extended to include dynamic testing. The disadvantage is that the maximum load that can be applied is limited to what a vehicle can carry. Some special testing vehicles with a larger load capacity (Steffens et al. 2001) have been developed, see for example Figure 1, and in some cases military vehicles and tanks (Varela-Ortiz et al. 2013) have been used.

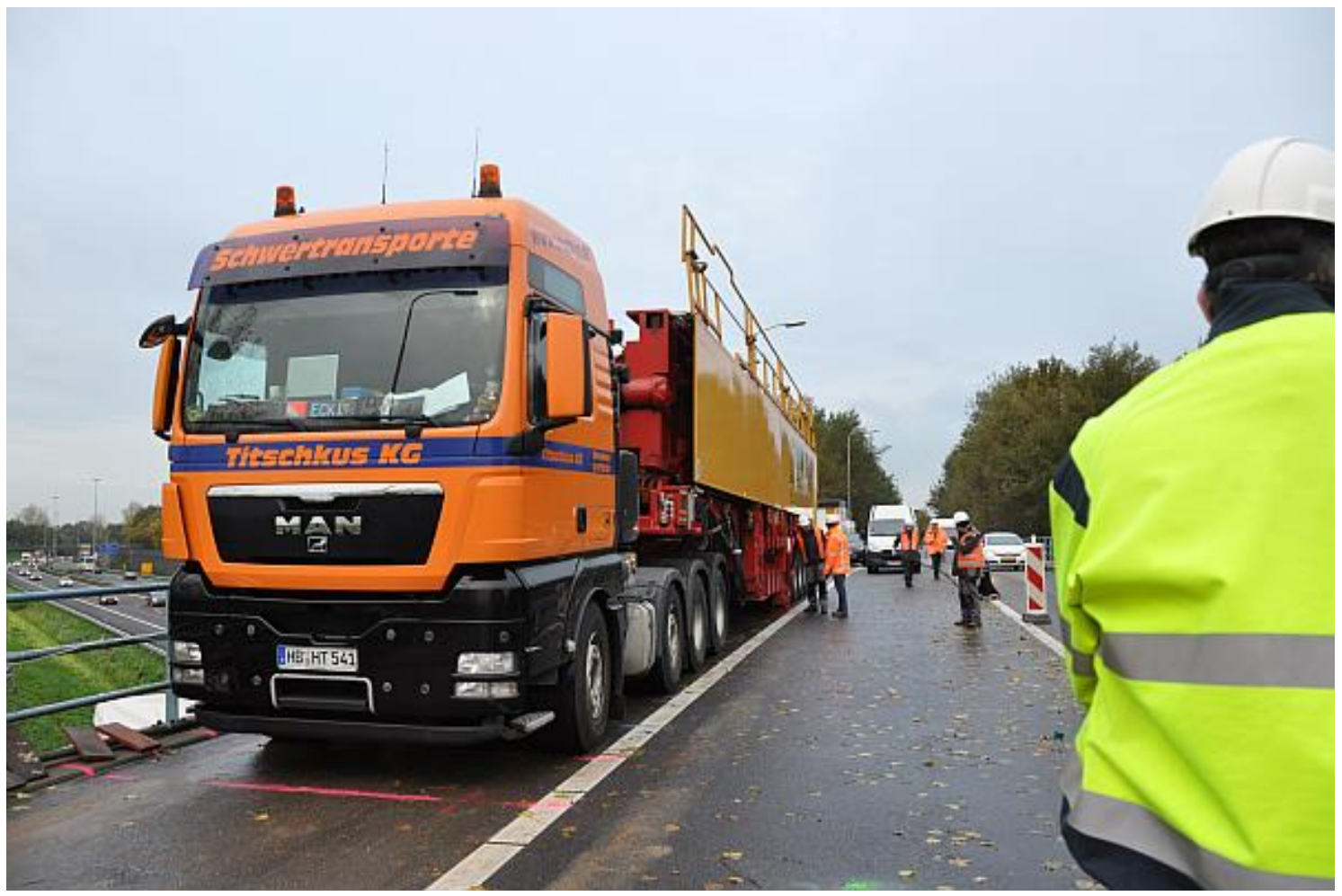

Figure 1. Example of special loading vehicle. Photograph by D.A. Hordijk, used with permission.

The required weight and number of test vehicles needs to be determined in function of the goals of the load test. For a diagnostic load test, the applied loading vehicles should cause load effects in the structure and/or critical structural element that correspond to service load levels. It's important for diagnostic load tests that the weight is large enough and represents the highest service load, so that structural behavior that may change depending on the loading level can be correctly evaluated (for example, transverse distribution and unintended composite action). Figure 2 shows an example of using multiple trucks to carry out a diagnostic load test prior to opening a steel box girder bridge built with the incremental launching technique (Bonifaz et al. 2018). 


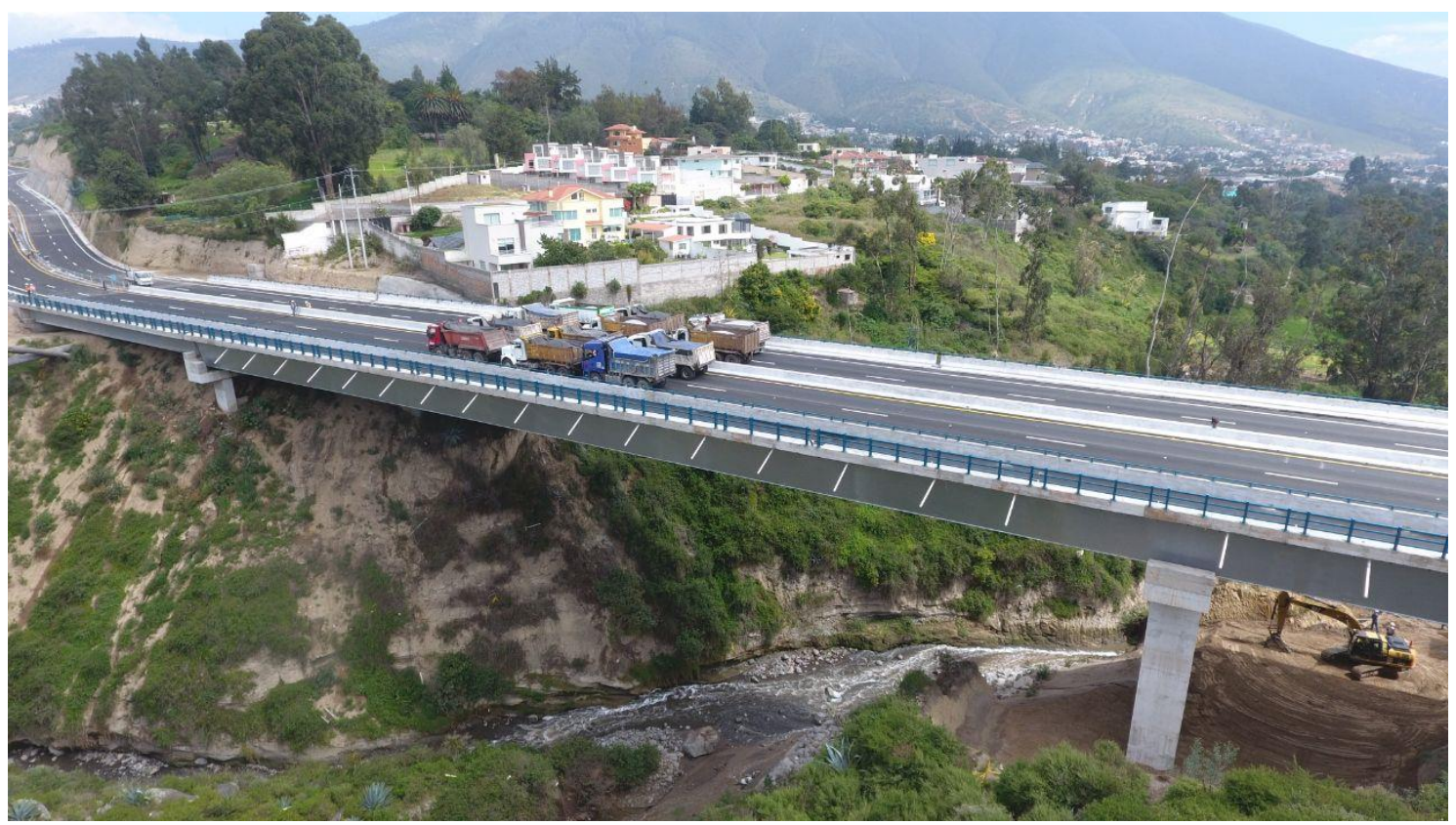

Figure 2. Load testing of a new bridge prior to opening with trucks - Villorita Bridge, Quito, Ecuador. Photograph by T.A. Sanchez. Used with permission.

For a proof load test, the applied loading vehicles should cause load effects in the structure and/or critical structural element that correspond to the effect of the factored loads used in design or assessment. For proof load testing the applied weight is of the utmost importance, as the magnitude of the target proof load is the measure that is used to directly assess the bridge with the field test. The determination of the weight and number of test vehicles thus results from the analysis calculations carried out as part of the preparation stage. It is good practice that this analysis considers the code-prescribed loads used for design (for new bridges) or assessment (for existing bridges), as well as special permit vehicles and other heavy vehicles that are using the bridge or that will use the bridge. Such an analysis during the preparation stage also leads to an indication of how the load compares to the maximum expected live load on the considered bridge.

When vehicles are used for dynamic testing, the structural response can be measured for different driving speeds to determine the dynamic amplification. To determine the damping after impact, a bump can be placed on the bridge deck, and the structural response from driving over the bump can be determined.

The use of hydraulic jacks for load testing is limited to proof load tests where loading vehicles cannot provide the axle layout or target load required to investigate the critical stress state and/or failure mode in a given structural element or the bridge structure. A system with hydraulic jacks has the preference for proof load testing of buildings under cyclic loads. For failure 
testing and research purposes, a system with hydraulic jacks is the preferred approach since such load is controllable, well defined, and can reach high magnitudes.

To determine the structural response of pedestrian bridges under moving live loads, a group of pedestrians can be used. These pedestrians are asked to stand on the bridge (static load test), to walk over the bridge, and to jog over the bridge (dynamic load test). Such tests typically are carried out on new bridges prior to opening (Ministerio de Fomento - Direccion General de Carreteras 1999, Beben and Anigacz 2014). In some cases, groups of cyclists are also used.

When the natural frequencies of a bridge need to be determined, an external source of excitation can be applied to the bridge to force vibration (Frýba and Pirner 2001). As such, the forced and free vibration shapes can be determined. For unusual bridge structures and long span bridges, the frequencies and modes of vibration should be compared to the analytically determined values (Cunha et al. 2016).

\section{MEASUREMENT EQUIPMENT}

\subsection{Measurement requirements}

Typically, structural design and assessment approaches use sectional moments and forces, and second-order-effect evaluations as a means to evaluate stress states of the structural elements. These values are of great importance when verifying and evaluating a response of the tested structure. In-situ testing can be extremely challenging due to difficulties in assessing the structure, environmental exposure, short time for testing etc. It is difficult to measure sectional moments and forces and second-order-effect directly during a load test. Reaction forces can be measured when load cells are installed at the supports, which may be an option for particular new bridges, but would require challenging jacking operations for existing bridges.

Structural responses (strains, deflections, and in concrete bridges, cracking) are typically measured and compared to calculated responses. The preparation stage of a load test includes preliminary calculations to predict the expected structural response during the test for the determined sectional moments and forces. This analysis should be carried out based on measured average material properties, take the observed damage and deterioration from the technical inspection into account, and is usually carried out with a linear finite element model, see also Chapter 5. The output from the finite element model can also be used for comparison to the field measurements after the test, see Figure 3. Based on the expected structural response and considering the goals of the load test, the sensor plan can be developed, see also Chapter 5. The ex- 
pected responses can be used for verification and/or to develop a stop criterion prior to a proof load test.

Since all measurements are zeroed at the beginning of the load test, only the response caused by the applied load is measured. The response under the permanent loads should be calculated and added to the measured response for evaluation and assessment. For newly designed bridges, the response due to the applied load can be directly compared to the expected response based on the analytical models that were used for the design. An example of the loaded area and measured deformations using digital image correlation is shown on Figure 4 which indicates the load separation and surface deformations (Schmidt et al. 2018).

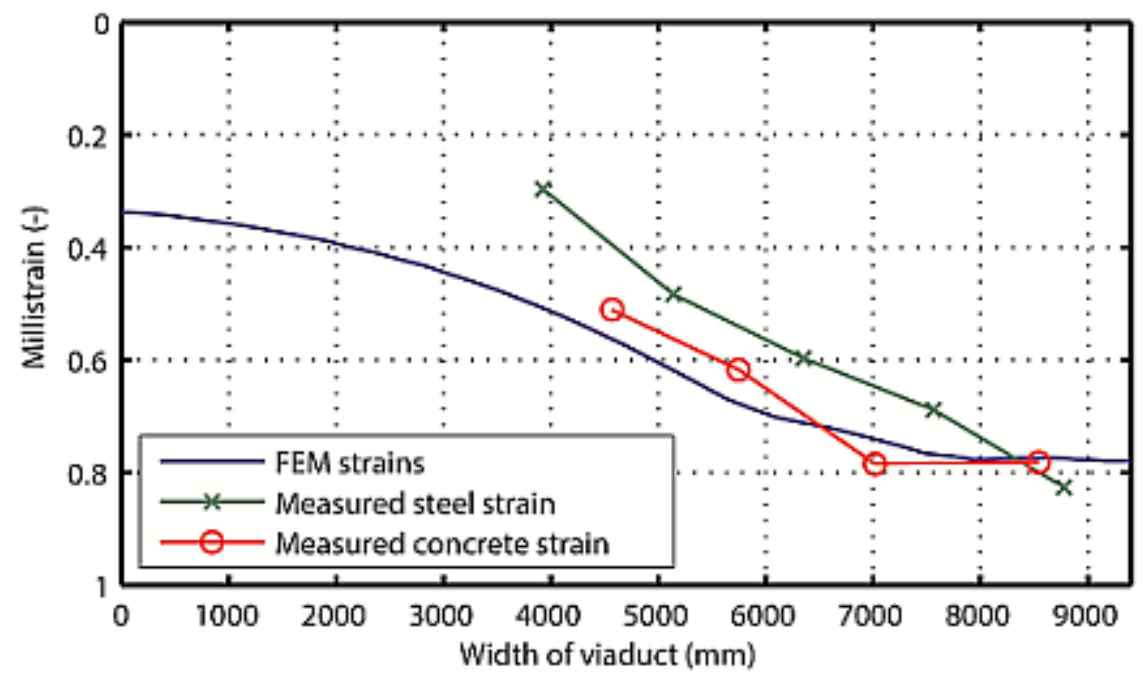

Figure 3. Comparison between results from linear finite element model and strains measured during field test. Conversion: $1 \mathrm{~mm}=0.04$ in. 


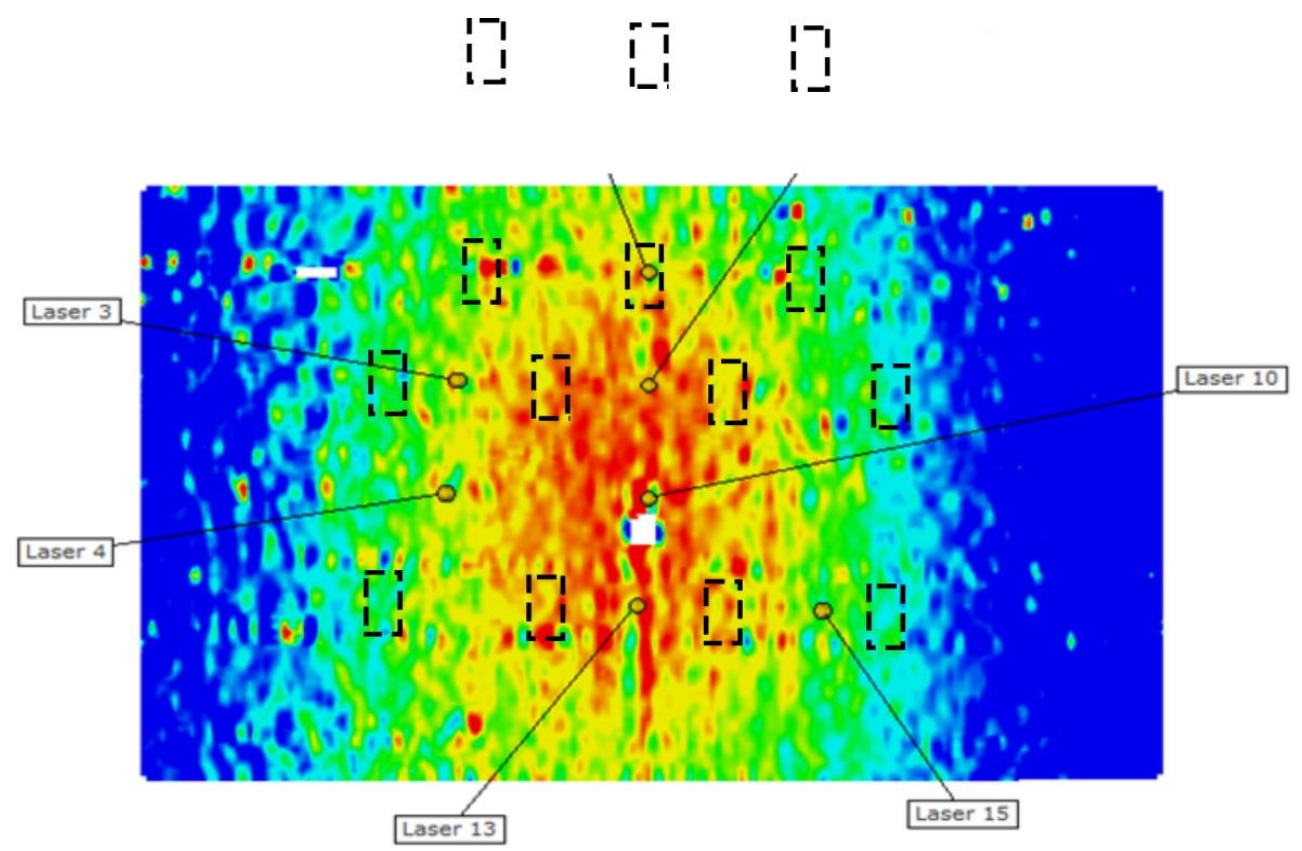

Figure 4. Example of the loaded area and measured deformations

\subsection{Data acquisition and visualization equipment}

A data acquisition and visualization system, containing amplifiers, data loggers, analog-todigital converters, and software for data visualization is necessary when the structural responses need to be monitored in real time during the load test. Therefore, the choice for the type and complexity of the data acquisition and visualization equipment should be made based on the type of load test and its goals. For example, for proof load testing, when stop criteria need to be evaluated in real time, real-time data visualization (see Figure 5) is of the utmost importance and all important parameters and plots showing the relations between the parameters should be preprogramed prior to the test. 


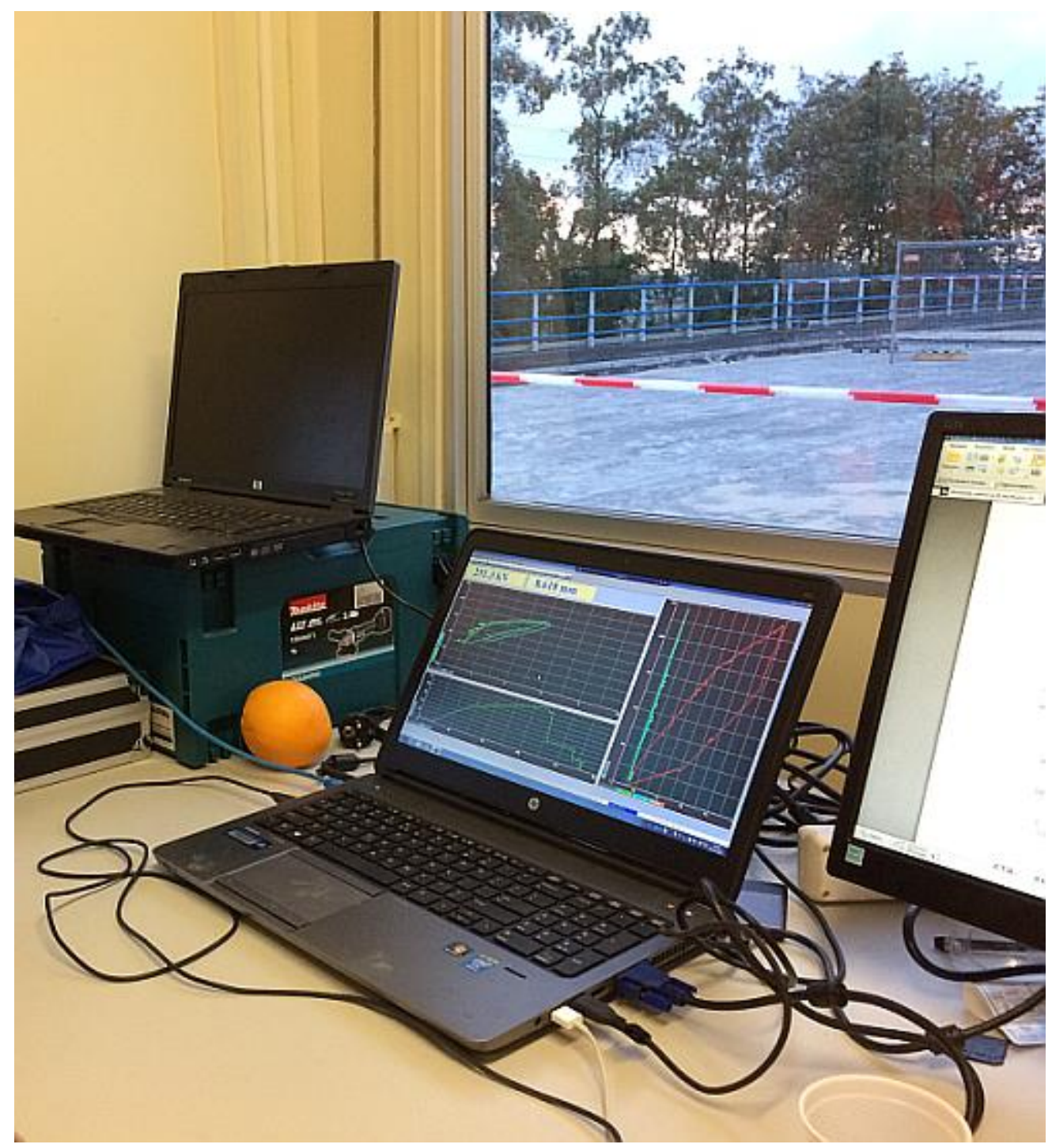

Figure 5. Real-time data visualization as part of a data acquisition and visualization system.

For load testing, the data acquisition and visualization system should be suitable for outdoor conditions. The sensitive equipment should be protected against the environmental effects. A military grade computer can be useful for running the data visualization software. The data acquisition equipment can be built into robust weatherproof boxes, stored in robust weatherproof boxes (as shown in Figure 6), or adequately covered. The operation of the data acquisition and visualization system should be independent of the weather conditions and should be guaranteed under conditions such as rain, wind, humidity etc... 


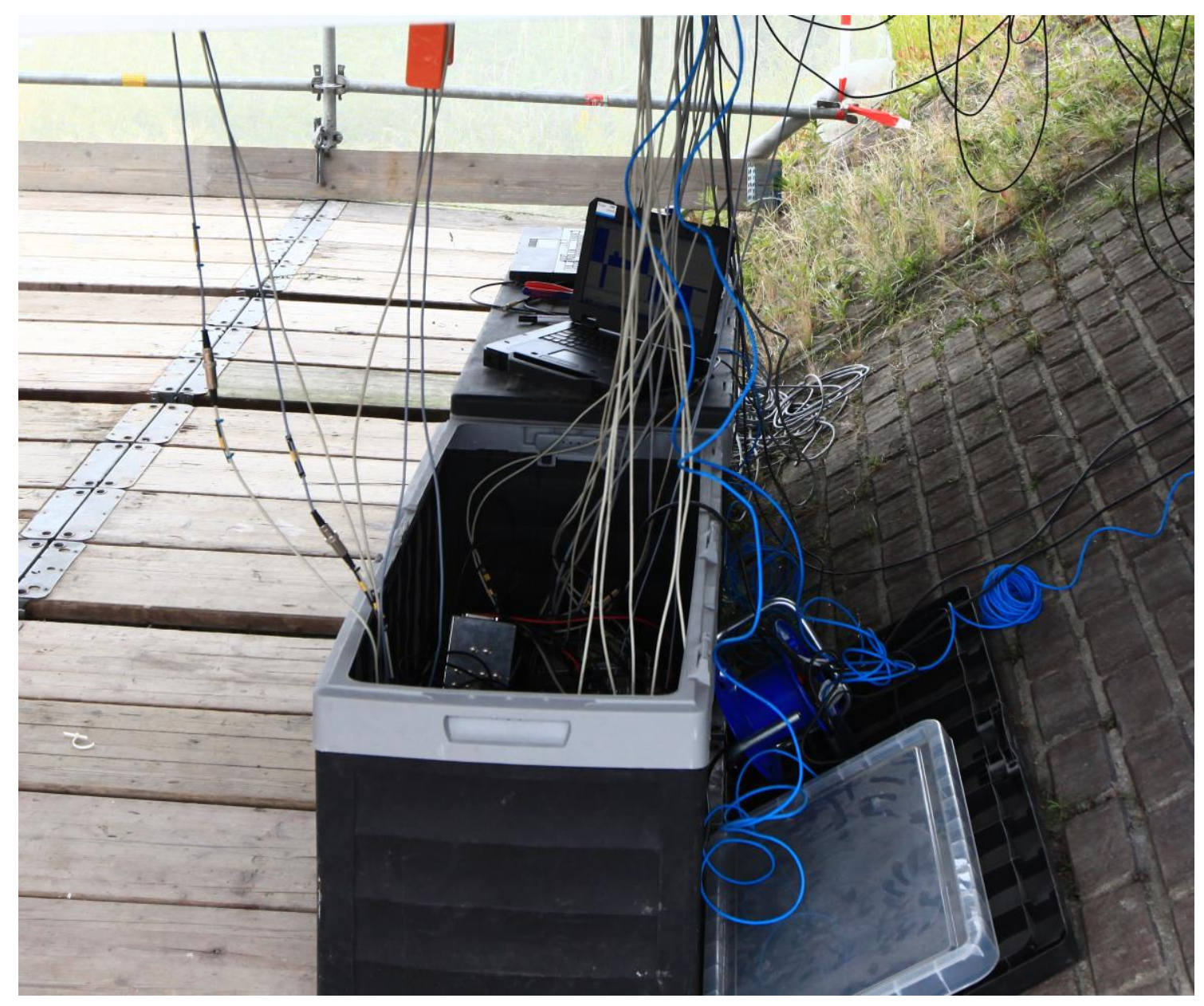

Figure 6: Use of weatherproof boxes for data acquisition system.

The type of load test and its goals drives the sampling rate of the sensors as well as the sampling rate of the data acquisition equipment. When cycles of loading are used to different magnitudes (for example in a proof load test when the load is applied with hydraulic jacks), the structural responses during loading and unloading should be captured, which requires a higher sampling rate. During a dynamic load test, the speed of loading and unloading may be even faster, requiring an even higher sampling rate. Reversely, during a monotonic loading protocol when the load is kept constant for a long period of time (for example, when the standard monotonic loading protocol for proof load testing of concrete buildings according to ACI 437.2M-13 (ACI Committee 437 2013) is used), a lower sampling rate is sufficient.

The data visualization software requires as input the calibration factors of all sensors. These factors should be determined with a calibration prior to the load test. Before the beginning of the planned load test, a test run should be done to check the proper functioning of all sensors and the data acquisition and visualization system. The output should be checked to see if the sensors are registering responses, and if these responses fall within the range of expected values. If this 
is not the case, an explanation for these observations should be sought and remedied where necessary.

In order to visualize the relation between the structural responses and the applied load or the position of the load, the data acquisition system should gather the output of the applied sensors as well as the information from the position or magnitude of the load. These values should then be processed together in the data visualization software.

\subsection{Sensors}

A large number of sensors (both contact and non-contact sensors) exists. Since the possibilities and tools rapidly change, this section only describes the requirements for the sensors. A recent overview of available sensors can be found in (Ettouney and Alampalli 2012). Depending on the goals of the load test, tried-and-tested sensors (such as strain gages) can be used, or cutting-edge measurement techniques can be used. Often, a combination of different sensors is used, and when new technologies are explored, the same structural response is often also measured with tried-and-tested sensors for comparison and evaluation. Examples of using new sensor types and measurement techniques for the practice of load testing are given in Part VI of this book.

In addition to the structural responses that are monitored during the load test and which are discussed in Chapter 5, the applied load can be measured. Whether or not this measurement is required depends on the goals of the load test. When vehicles are used, the position of the load can be measured with trackers and used to compare to the position of the structural responses. The magnitude of the load is then determined before each run of the vehicle or group of vehicles by weighing the trucks. When hydraulic jacks are used to apply a cyclic loading protocol, the magnitude of the load can be measured with load cells. The position of the load is then determined prior to the test and is a single position, and needs not to be monitored during the load test.

\subsection{Interpretation of measurements during load test}

The importance and required extent of the interpretation of measurements during load tests depends on the goals of the load test. For some types of diagnostic load testing, no real-time visualization of the measurements is required, and therefore no interpretation of these measurements is done. For proof load testing, on the other hand, a crucial aspect for a safe execution of the load test are the stop criteria. These thresholds need to be evaluated during the proof load test. The topic of stop criteria is further discussed in Part IV. 


\subsection{Communication}

For a safe and timely execution of a load test, communication between all parties involved is crucial. Prior to the load test, all parties involved in the field should meet and talk through the practical details of the test. The workflow processes during the test should be determined in this meeting, written down, distributed to all parties involved, and be visible to all parties during the load test. These descriptions should include the responsible person for the different decisions during the load test, and the lines of communication during the load test. During the execution of the load test, all parties involved should be able to communicate, for example by using walkie-talkies and cellphones (see Figure 7).

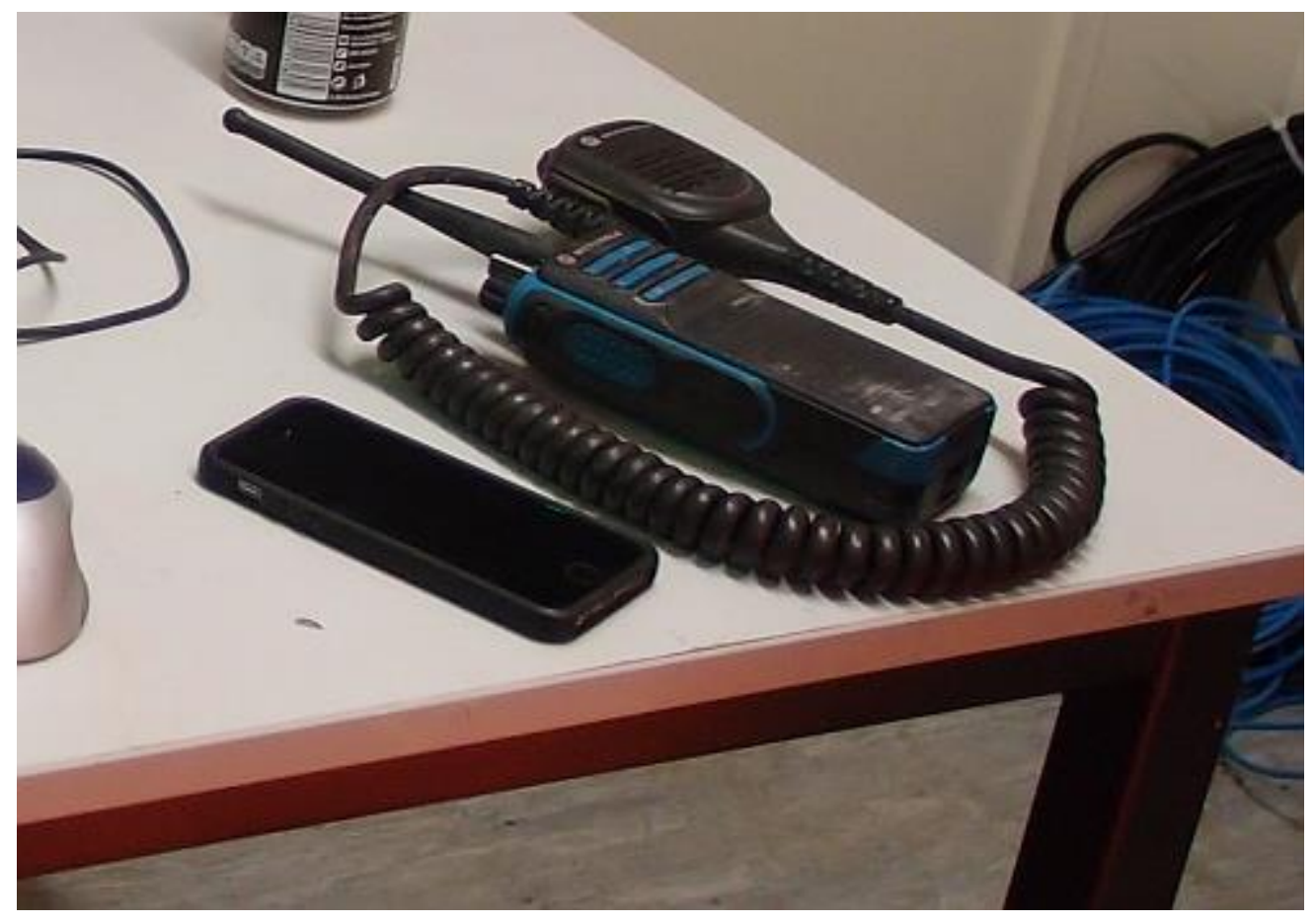

Figure 7. Means of communication during load test.

When the load is applied with trucks, the required driving path and speed should be clearly communicated to the drivers. When the load is applied with dead loads or hydraulic jacks, the responsible engineer should give the permission to increase the load prior to each load step. For a proof load test, the responsible engineer makes this decision based on the analysis of the measurements and stop criteria. 


\subsection{Safety}

Safety is of crucial importance during a load test. In Chapter 4, all considerations that need to be addressed before deciding if a load test can be carried out are summarized. In Chapter 5, the elements that need to be considered during the preparation stage are discussed. In this Chapter, the important safety considerations related to the execution stage of the load test are highlighted.

Safety considerations are an important part of the preparation stage, and all elements of the execution should be thought through so that the load test can be carried out as safe as possible. All information on what to do in case of accidents or calamities should be communicated to all personnel that will carry out activities on site, and the address and phone number of emergency services, the nearest pharmacy, doctor, and hospital, firefighters, and police should be clearly displayed. A list with names of personnel that is allowed on site from all parties involved can be made to make sure no unauthorized people access the site. Upon arrival to the test site, personnel should register with the safety engineer, and upon leaving the test site, they should also register the time of leaving the site to have a log of the personnel present on site.

For a safe execution of the load test, the following considerations should be taken into account:

- All personnel involved on site should receive a safety briefing before starting any activities.

- All personnel involved on site should be wearing the correct personal protective equipment.

- Sufficient light for night activities should be provided.

- Safe access to the bridge structure and the locations where sensors are applied should be provided.

- At all times, a person with a first aid qualification should be on site.

- A short briefing every morning before the start of activities to revise the main safety concerns and discuss the actions for the day, is recommended.

- After the load test, an evaluation meeting in which the safety and execution procedures are discussed, is recommended. 
At all times, the minimum required personal protective equipment include safety shoes, hard hat, and reflective jacket. A life vest is necessary for activities close to water, see Figure 8. Safety goggles and hearing protection should be available and used for specific tasks.

Safe access to the bridge structure and sensor locations can include a pontoon for activities on bridges over water, or scaffolding. These temporary structures should be checked every day by the safety engineer.

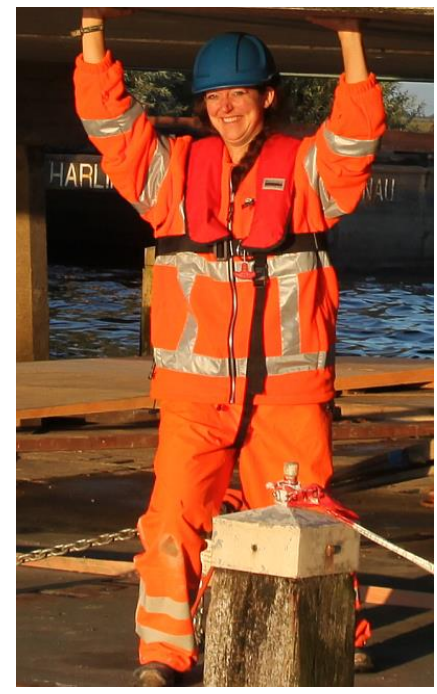

Figure 8. Safety shoes, life jacket, hard hat, and protective clothing for load test.

Safe access to the bridge location is also important, and the access routes to the bridge should be communicated with all parties involved. Parking space should be available on site. If the bridge is closed for traffic (see Figure 9), all signposting for the detour should be in place before the activities on site start and before access to the bridges is restricted.

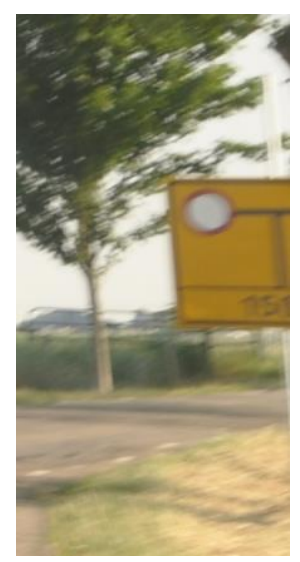

Figure 9. Signposting for detour during load test. Excerpt from Photograph by D.A. Hordijk. Used with permission. 


\section{SUMMARY AND CONCLUSIONS}

This chapter summarizes general considerations for the execution of load tests, regardless the type of load test. Particularities for diagnostic load tests and proof load tests are discussed in Part III and IV, respectively.

The first general element for all load tests is that load is applied. Different methods and types of equipment for applying the load are available. In most cases, loading vehicles (trucks or a special vehicle) are used. Other options include using dead load, hydraulic jacks, a group of pedestrians, or an exciter (for modal analysis). The choice for a method and type of equipment depends on the goals of the load test.

A second general element for all load tests is that the structural response caused by the applied loads is measured. These responses can be monitored in real time or analyzed after the load test, depending on the type of load test and the objectives of the load test.

Finally, this chapter discusses practical aspects during the load test. The most important elements here are communication and workflow lines, and safety. While again these aspects depend on the particularities of the load test, some best practices and general considerations are discussed in this chapter.

\section{REFERENCES}

ACI COMMITTEE 437 2013. Code Requirements for Load Testing of Existing Concrete Structures (ACI 437.2M-13) and Commentary Farmington Hills, MA.

BEBEN, D. \& ANIGACZ, W. 2014. Interferometric radar application for dynamic testing of bridge structures. IABMAS 2014. Foz de Iguacu, Brazil.

BONIFAZ, J., ZARUMA, S., ROBALINO, A. \& SANCHEZ, T. A. 2018. Bridge Diagnostic Load Testing in Ecuador - Case Studies. IALCCE 2018. Ghent, Belgium.

CUNHA, A., CAETANO, E., MAGAlHÃES, F. \& MOUTINHO, C. 2016. Dynamic Identification and Continuous Dynamic Monitoring of Bridges. In: BITTENCOURT, FRANGOPOL \& BECK (eds.) Maintenance, Monitoring, Safety, Risk and Resilience of Bridges and Bridge Networks. Foz do Iguacu, Brazil.

ETTOUNEY, M. \& ALAMPALLI, S. 2012. Infrastructure health in civil engineering, Boca Raton, FL, CRC Press. 
FRÝBA, L. \& PIRNER, M. 2001. Load tests and modal analysis of bridges. Engineering Structures, 23, 102-109.

MINISTERIO DE FOMENTO - DIRECCION GENERAL DE CARRETERAS 1999. Recomendaciones para la realizacion de pruebas de carga de recepcion en puentes de carretera.

SCHMIDT, J. W., HALDING, P. S., JENSEN, T. W. \& ENGELUND S. 2018. High Magnitude Loading of Concrete Bridges, ACI Special publication, Evaluation of concrete bridge behaivour through load testing - International perspectives. SP-323-9, 9.1-9.20

STEFFENS, K., OPITZ, H., QUADE, J. \& SCHWESINGER, P. 2001. The loading truck BELFA for loading tests on concrete bridges and sewers (in German). Bautechnik, 78, 391-397.

VARELA-ORTIZ, W., CINTRÓN, C. Y. L., VELÁZQUEZ, G. I. \& STANTON, T. R. 2013. Load testing and GPR assessment for concrete bridges on military installations. Construction and Building Materials, 38, 1255-1269.

ZHOU, Y. E., CUPPLES, T. H., BROWN, R. \& HWANG, G. 2007. Re-evaluation of Weight Limits for Six Bridges in Montgomery County Maryland. IBC 2007. 